\title{
Drying Shrinkage Behaviour of Fibre Reinforced Concrete Incorporating Polyvinyl Alcohol Fibres and Fly Ash
}

\author{
Amin Noushini, Kirk Vessalas, Garo Arabian, and Bijan Samali \\ Centre for Built Infrastructure Research (CBIR), School of Civil and Environmental Engineering, University of Technology Sydney, \\ P.O. Box 123, Broadway, Sydney, NSW 2007, Australia
}

Correspondence should be addressed to Amin Noushini; a.noushini@gmail.com

Received 24 December 2013; Revised 13 April 2014; Accepted 1 May 2014; Published 20 May 2014

Academic Editor: Serji N. Amirkhanian

Copyright (C) 2014 Amin Noushini et al. This is an open access article distributed under the Creative Commons Attribution License, which permits unrestricted use, distribution, and reproduction in any medium, provided the original work is properly cited.

The current study assesses the drying shrinkage behaviour of polyvinyl alcohol fibre reinforced concrete (PVA-FRC) containing short-length $(6 \mathrm{~mm})$ and long-length $(12 \mathrm{~mm})$ uncoated monofilament PVA fibres at $0.125 \%, 0.25 \%, 0.375 \%$, and $0.5 \%$ volumetric fractions. Fly ash is also used as a partial replacement of Portland cement in all mixes. PVA-FRC mixes have been compared to length change of control concrete (devoid of fibres) at 3 storage intervals: early-age (0-7 days), short-term (0-28 days), and longterm (28-112 days) intervals. The shrinkage results of FRC and control concrete up to 112 days indicated that all PVA-FRC mixes exhibited higher drying shrinkage than control. The shrinkage exhibited by PVA-FRC mixes ranged from 449 to 480 microstrain, where this value was only 427 microstrain in the case of control. In addition, the longer fibres exhibited higher mass loss, thus potentially contributing to higher shrinkage.

\section{Introduction}

Concrete is recognised as the most prevalent used construction material in the world [1]. It is reputable that concrete provides notable mechanical performance, great versatility, and economic efficiency in comparison to other construction materials [2]. However, it must be noted that concrete is discredited for its brittleness and strength-to-weight ratio. Moreover, in service, structural concrete undergoes volume change due to moisture loss by hydration and evaporation. This volume change and movement experienced in this manner is termed shrinkage [2].

Shrinkage of concrete commonly occurs as a decrease in volume via four primary mechanisms: capillary tension, surface tension, disjoining pressure, and change in water within the matrix of cement [3]. Concrete tends to reach equilibrium with its service environment. If the environment is a dry atmosphere the exposed surface of the concrete loses water by evaporation. The rate of evaporation will depend on the relative humidity, temperature, water-cement ratio, and the area of the exposed surface of the concrete $[4,5]$. The first water to be lost from concrete is that held in the large capillary pores of the hardened concrete. The loss of this water does not cause significant volume change [6].

However, as explained by Tam et al. [7], as water continues to evaporate from the capillary and gel pores, a meniscus is formed along the network of capillary pores and surface tension is created. With the reduction in the vapour pressure in the capillary pores, tensile stress in the residual water increases. These tensile stresses are in equilibrium with compressive stresses acting in the surface layers of the concrete, and hence shrinkage of the concrete occurs (i.e., deformation). Evaporation of water from the gel pores of the surface of concrete causes additional shrinkage on the surface. Drying shrinkage is a part of this deformation.

The hardened cement paste contains a gel known as calcium silicate hydrate (C-S-H) gel. When this gel contracts the moisture content decreases, which in turn causes a drying shrinkage effect within the concrete [8]. The concrete will try to reach equilibrium with its environment after the cement has hydrated. There exist a number of dependent factors influencing the degree of shrinkage such as raw material properties (e.g., cement, aggregate, and admixtures), temperature, relative humidity $(\mathrm{RH})$, age, and volumetric size of the concrete member [9]. 
It has been of particular focus by researchers $[2,10-13]$ in recent times to minimise the aforementioned problems of shrinkage by utilising intrinsic fibres as a form of reinforcement in the concrete matrix. The use of novel synthetic fibres such as monofilament polyvinyl alcohol (PVA) fibres in fibre reinforced concrete (FRC) can affect the overall properties of hardened concrete [14-16], with drying shrinkage being of particular interest. However, the exact influence of fibre length and volumetric content remains unknown.

Polyvinyl alcohol (PVA) is adopted from polyvinyl acetate, which is readily hydrolysed by treating an alcoholic solution with aqueous acid or alkali [17]. PVA contains hydroxyl groups $(\mathrm{OH})$ which have the potential to form hydrogen bonds between molecules resulting in a significant change in surface bond strength between PVA fibres and the cement matrix [18].

The use of fibres in concrete mixes (FRC) is generally seen as a prevention method for cracks formed in the surface layers of the hardened concrete $[19,20]$. Fibres allow the bridging of cracks, which aids in increasing the ductility of the concrete composite after the postcracking stage [21,22]. The fibre in concrete aims to produce stronger and tougher concrete, particularly improving the ductility and durability and mitigating cracking due to shrinkage [23]. Fibres have also been reported [24] to increase the fatigue life cycle of cementitious composite structures. Fibres incorporated in concrete are known to control cracking arising from drying and/or plastic shrinkage behaviour occurring in the cementitious matrix $[25,26]$.

The mitigation of drying shrinkage aids the concrete aesthetically and also by controlling and preventing shrinkage cracks the durability of concrete can be enhanced [2]. The spalling of concrete caused by cracking from shrinkage will expose the steel reinforcement to aggressive chemicals such as chloride ions dissociated in water to penetrate the surface of the concrete, reach the steel, and cause corrosion [27]. Cracking from shrinkage is a rather complex mechanism of deformation that is influenced by factors such as size of the crack, level of restraint, rate of shrinkage, development of strength, and softening of the stress [2].

Although the shrinkage characteristics of conventional concrete have been widely studied $[4,28]$ and the relationship between shrinkage and mass loss due to drying is well established for conventional concrete, limited research has been conducted on the drying shrinkage behaviour of PVA fibre reinforced concrete.

Accordingly, the objective of this study is to quantify the amount of shrinkage experienced and impart the variations of fibre length, aspect ratio, and content to drying shrinkage of PVA-FRC.

\section{Experimental Details}

2.1. Materials. Seven sets of concrete mixes were prepared using the raw materials shown in Table 4. Shrinkage limited (SL) Portland cement (PC) and fly ash (FA) were used as the binder for the fibre reinforced concrete mixes. The fineness of FA by $45 \mu \mathrm{m}$ sieve was determined to be $94 \%$ passing (tested

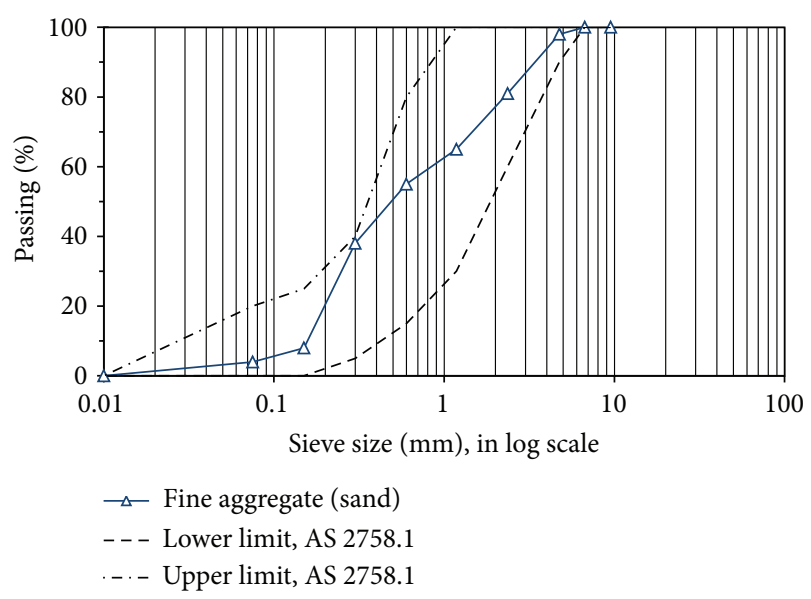

FIGURE 1: Fine aggregate grading curve.

in accordance with AS 3581.1-1998). The oxide compositions of the binders are listed in Table 1.

A maximum nominal size of $20 \mathrm{~mm}$ aggregate was used in all mixes. All aggregates used in mix design were sourced from Dunmore, Australia, which include 50/50 blended fine/coarse manufactured sand and $10 \mathrm{~mm}$ and $20 \mathrm{~mm}$ crushed latite gravel. The grading of all aggregates used in this study complied with the Australian Standard AS 2758.1 specifications and limits (Figures 1 and 2).

The aggregate was prepared to saturated surface dry condition prior to mixing. Drinkable grade tap water was used for the mixes after conditioning the water to room temperature $\left(23 \pm 2^{\circ} \mathrm{C}\right)$. Furthermore, in order to improve the workability, a polycarboxylic ether based high range water reducing admixture (HWR) was used. Monofilament uncoated polyvinyl alcohol fibre of 2 different geometries, 6 and $12 \mathrm{~mm}$, with properties mentioned in Table 2 and the graphical illustration shown in Figure 3, was used in all FRC mixes.

2.2. Mixing. Mix designs were adopted to obtain a characteristic compressive strength $\left(f_{c}^{\prime}\right)$ of $55 \mathrm{MPa}$ to conform to AS 3600 requirements as structural concrete (ranging from $20 \mathrm{MPa}$ to $100 \mathrm{MPa}$ ) with a water to cementitious material ratio $(w / c)$ of 0.35 . In order to obtain a desired slump of $80 \pm 20 \mathrm{~mm}$, HWR dosage was varied. Mix designations are shown in Table 3 and details of the mix proportions for all mixes are listed in Table 4.

Mix proportioning of the raw material ingredients was carried out by mass. The fibre volume fractions employed in this study were up to a threshold limit of $0.5 \%$; this limit was derived from the results of several preliminary trial mixes indicating that the incorporation of higher volume fraction of fibres results in loss of cohesiveness of the concrete.

For control concrete (nonfibre reinforced concrete), mixing was performed in accordance with Australian Standard AS 1012.2; however, for FRC mixes, due to the presence of the hydrophilic fibres, the standard mixing regime suggested in AS 1012.2 for conventional concrete was modified. Fine aggregates were firstly mixed with PVA fibres in a vertical 
TABLE 1: Chemical properties of PC and FA by X-ray fluorescence method.

\begin{tabular}{lcccccccccccc}
\hline & $\mathrm{SiO}_{2}$ & $\mathrm{Al}_{2} \mathrm{O}_{3}$ & $\mathrm{Fe}_{2} \mathrm{O}_{3}$ & $\mathrm{CaO}$ & $\mathrm{MgO}$ & $\mathrm{Na}_{2} \mathrm{O}$ & $\mathrm{K}_{2} \mathrm{O}$ & $\mathrm{TiO}_{2}$ & $\mathrm{MnO}_{2}$ & $\mathrm{P}_{2} \mathrm{O}_{5}$ & $\mathrm{SO}_{3}$ & $\mathrm{LOI}$ \\
\hline PC [wt.\%] & 20.16 & 4.62 & 4.56 & 65.35 & 1.06 & - & 0.44 & 0.28 & 0.60 & 0.07 & 2.55 & 1.16 \\
FA [wt.\%] & 65.13 & 23.75 & 3.38 & 1.92 & 0.49 & 0.48 & 1.46 & 0.92 & 0.07 & 0.25 & 0.07 & 1.65 \\
\hline
\end{tabular}

TABle 2: Properties of PVA fibres.

\begin{tabular}{lcccccc}
\hline Type & $\begin{array}{c}\text { Density } \\
{\left[\mathrm{g} / \mathrm{cm}^{3}\right]}\end{array}$ & $\begin{array}{c}\text { Length }\left(L_{f}\right) \\
{[\mathrm{mm}]}\end{array}$ & $\begin{array}{c}\text { Diameter }\left(d_{f}\right) \\
{[\mathrm{mm}]}\end{array}$ & $\begin{array}{c}\text { Tensile strength } \\
{[\mathrm{MPa}]}\end{array}$ & $\begin{array}{c}\text { Young's modulus }\left(E_{f}\right) \\
{[\mathrm{GPa}]}\end{array}$ & $\begin{array}{c}\text { Elongation } \\
{[\%]}\end{array}$ \\
\hline W2-6 & 1.29 & 6 & 0.014 & 1500 & 41.7 & 7 \\
W2-12 & 1.29 & 12 & 0.014 & 1500 & 41.7 & 7 \\
\hline
\end{tabular}

TABLE 3: Mix designations.

\begin{tabular}{lccc}
\hline Mix designation & Binder & $V_{f}^{1}[\%]$ & Fibre length $[\mathrm{mm}]$ \\
\hline Control & $70 \%$ PC + 30\% FA & 0 & - \\
6-PVA-0.125 & $70 \%$ PC + 30\% FA & 0.125 & 6 \\
6-PVA-0.250 & $70 \%$ PC + 30\% FA & 0.250 & 6 \\
6-PVA-0.375 & $70 \%$ PC + 30\% FA & 0.375 & 6 \\
6-PVA-0.500 & $70 \%$ PC + 30\% FA & 0.500 & 6 \\
12-PVA-0.125 & $70 \%$ PC + 30\% FA & 0.125 & 12 \\
12-PVA-0.250 & $70 \%$ PC + 30\% FA & 0.250 & 12 \\
12-PVA-0.375 & $70 \%$ PC + 30\% FA & 0.375 & 12 \\
12-PVA-0.500 & $70 \%$ PC + 30\% FA & 0.500 & 12
\end{tabular}

${ }^{1}$ Fibre volume fraction.

pan mixer until the fibres were observed to be dispersed uniformly. Coarse aggregates were then added and further mixed for 3 minutes. Thereafter, SL PC, FA, and water were introduced and mixed for a further 3 minutes. In order to adjust the slump, HWR was added within the first minute of adding cementitious material. Following 3 minutes of mixing, a rest period of 2 minutes was applied followed by a further 3 minutes of mixing to achieve a uniform mix. The slump and compacting factor were measured to deduce separate measures of workability.

After carrying out all fresh property tests, the mix was placed into moulds. In addition, an external vibrator was used to achieve proper consolidation and also to minimise the amount of the entrapped air arising within the mix. Moulds were covered with plastic sheets and wet towels to retain moisture, after finishing the surface of all specimens with a trowel. At $24 \mathrm{~h}$, specimens were demoulded and then placed in lime saturated water to cure at a temperature of $20 \pm 2^{\circ} \mathrm{C}$ until the date of testing.

2.3. Testing. Slump and compacting factor were carried out to determine the consistency following Australian Standard AS 1012.3.1 and AS 1012.3.2 test methods, respectively. In addition, air content and mass per unit volume were measured to study the effect of PVA fibres on the properties of concrete in its plastic state (AS 1012.4.2 and AS 1012.5).

The behaviour of the concrete under compressive load has also been assessed by conducting uniaxial compressive strength testing. Cylindrical specimens of 100 diameter $\times$

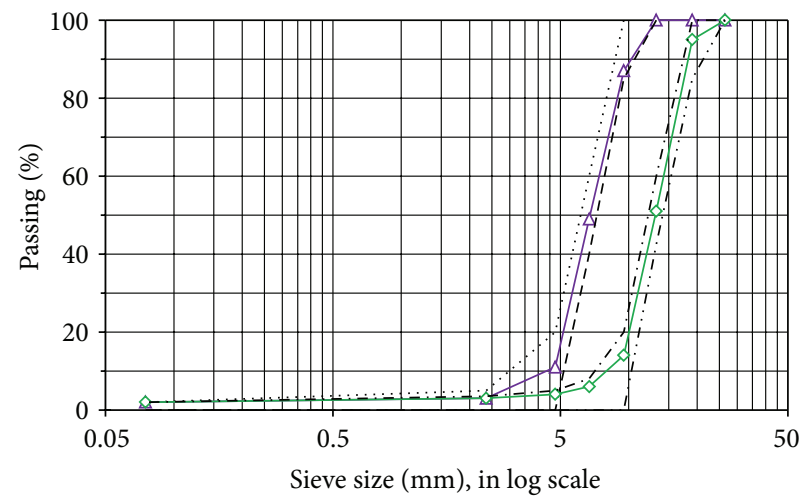

$$
\begin{aligned}
& \neg-10 \mathrm{~mm} \text { coarse aggregate } \multimap 20 \mathrm{~mm} \text { coarse aggregate } \\
& \text {..... Upper limit, AS 2758.1 . - - - Upper limit, AS 2758.1 } \\
& \text { - - - Lower limit, AS 2758.1 . - . L Lower limit, AS } 2758.1
\end{aligned}
$$

FIGURE 2: Coarse aggregate grading curve.

$200 \mathrm{~mm}$ height were tested under a load rate control condition in a $1800 \mathrm{kN}$ universal testing machine following AS 1012.9 (load rate equivalent to $20 \pm 2 \mathrm{MPa}$ compressive stress per minute). Compressive strength was determined at ages of 7, 28, and 56 days. The static chord modulus of elasticity (MOE) test was also carried out on 150 diameter $\times 300 \mathrm{~mm}$ height cylinders following Australian Standard AS 1012.17 test method.

The measuring of drying shrinkage was undertaken in accordance with Australian Standard AS 1012.13 test method criteria. The standard sized mould which was used in this study is shown in Figure 4. The gauge stud retaining screws (also known as shrinkage pins) were placed prior to moulding the concrete in shrinkage moulds.

For the initial reading of mass and gauge length, the sample was removed from the lime saturated water on the 7 th day from moulding and excess water was wiped with a damp cloth. A horizontal comparator was used to determine the horizontal length (gauge length). Five readings were taken for each specimen to minimise errors, following the procedure mentioned in Australian Standard AS 1012.13. The mass of each sample was also recorded in order to calculate the mass loss as a function of time. 


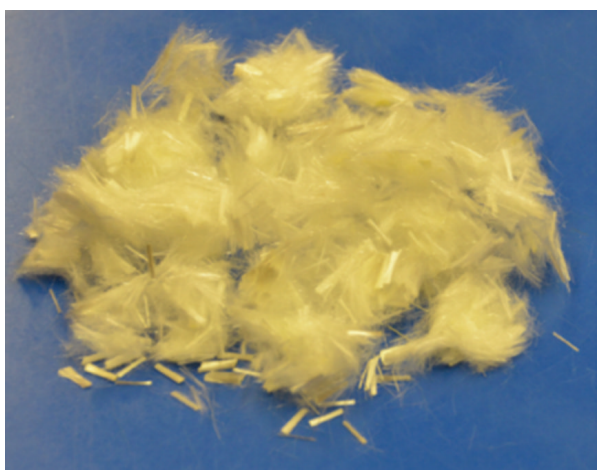

(a)

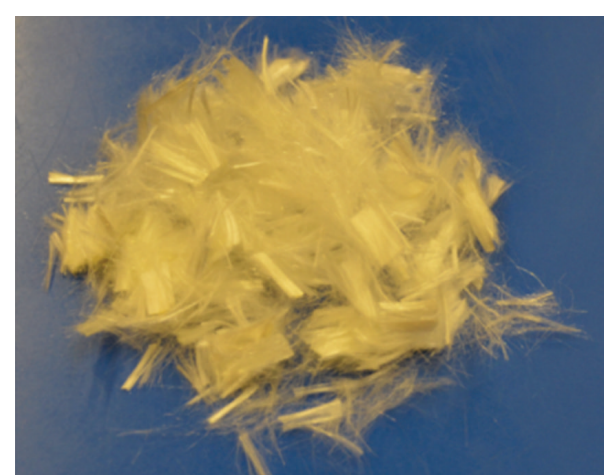

(b)

FIgURE 3: PVA fibres: $6 \mathrm{~mm}$ fibres and (a) $12 \mathrm{~mm}$ fibres (b).

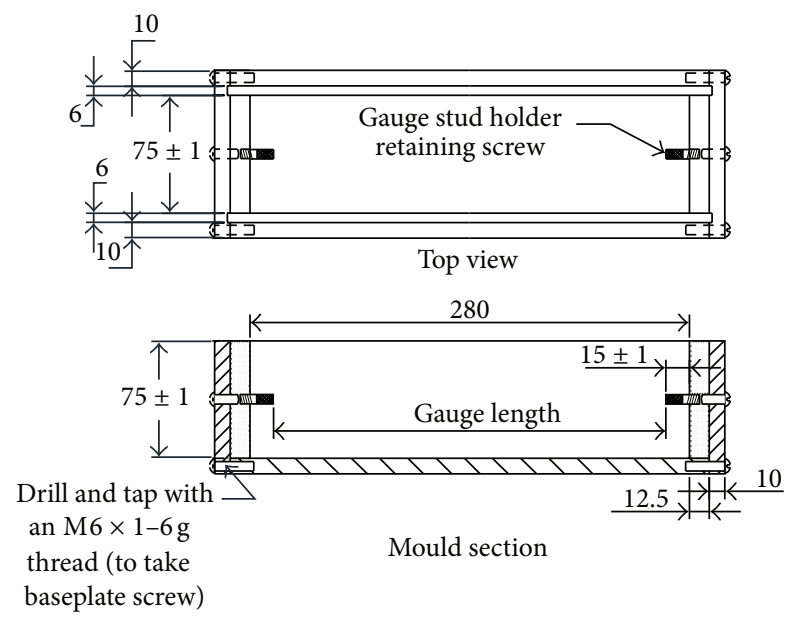

FIgURE 4: Details of a typical mould (AS 1012.12).

Equation (1) was used to determine the drying shrinkage strain at a particular time. Consider

$$
\varepsilon_{s, t}=\frac{L_{t}-L_{0}}{L_{g}},
$$

where $\varepsilon_{s, t}$ is the drying shrinkage strain at time $t, L_{t}$ is the specimen length measured at time $t$ in $\mathrm{mm}, L_{0}$ is the specimen initial length in $\mathrm{mm}$, and $L_{g}$ is the original gauge length (see Figure 4) in mm.

Specimens were stored on racks in a drying room with a controlled temperature of $23 \pm 1^{\circ} \mathrm{C}$ and a relative humidity of $50 \pm 5 \%$ for a period of 112 days. The shrinkage and mass loss readings were taken after 3 days and thereafter every 7 days until 112 days by which time most of the drying shrinkage had taken place.

\section{Results and Discussion}

3.1. Fresh Properties. Slump, compacting factor, air content, and mass per unit volume of different mixes were measured and results are summarised in Table 5 . It can be seen that as the volume of fibre increases, more HWR is required to achieve an acceptable slump. This observation has also been previously found by Zollo in that with a volumetric content of plastic fibres above or close to $0.5 \%$; the workability is known to significantly decrease due to greater interfacial actions during mixing between the fibres and cementitious materials in concrete [19].

By examining the recorded results displayed in Table 5, it can be deduced that the PVA-FRC mixes tend to introduce air when compared to the control concrete. The introduction of plastic fibres is known to create larger interstitial voids between the fibres, cement paste, and aggregates $[29,30]$.

Results from Table 5 also show that as the volume of fibre increases in the mix, the mass per unit volume of the concrete decreases. This is possibly due to the lower mass per unit volume of the fibres and higher entrapped air contents when the fibre volume increases. Results presented in Table 5 display that, by increasing the amount of fibre in the mix, the density decreases from $2450 \mathrm{~kg} / \mathrm{m}^{3}$ for control to $2300 \mathrm{~kg} / \mathrm{m}^{3}$ for 12-PVA-0.500. The decrease noted in the mass per unit volume is highly dependent on the volume and amount of fibres in the matrix as well as the length and number of fibres. It is also understandable that in the same fibre volume fraction, $12 \mathrm{~mm}$ fibres affect the MPV more than $6 \mathrm{~mm}$ fibres, which may be attributed to the higher aspect ratio of longer fibres.

3.2. Hardened Properties. The compressive strength of control and FRC with different fibre volume fractions ranging from $0.0 \%$ to $0.5 \%$ at 7,28 and 56 days of age are presented in Table 6 and Figure 5. Standard deviation calculated for compressive strengths of each concrete set show the level of variation from average strength reported out of 3 specimens tested for each age. A low standard deviation indicates that the individual compressive strength of test specimens tends to be very close to the average strength of that set which makes a higher level of confidence in statistical average strength reported. Strength effectiveness which is defined as the percent increase or decrease in the strength of FRC compared to the control at the same age has also been calculated. 
TABLE 4: Mix proportions.

\begin{tabular}{lccccccccc}
\hline $\begin{array}{l}\text { Mix } \\
\text { designation }\end{array}$ & PC $\left[\mathrm{kg} / \mathrm{m}^{3}\right]$ & FA $\left[\mathrm{kg} / \mathrm{m}^{3}\right]$ & $\begin{array}{c}\text { Sand } \\
{\left[\mathrm{kg} / \mathrm{m}^{3}\right]}\end{array}$ & $\begin{array}{c}10 \mathrm{~mm} \\
\text { aggregates } \\
{\left[\mathrm{kg} / \mathrm{m}^{3}\right]}\end{array}$ & $\begin{array}{c}20 \mathrm{~mm} \\
\text { aggregates } \\
{\left[\mathrm{kg} / \mathrm{m}^{3}\right]}\end{array}$ & $\begin{array}{c}\text { Water } \\
{\left[\mathrm{kg} / \mathrm{m}^{3}\right]}\end{array}$ & $\begin{array}{c}\text { HWR } \\
{\left[\mathrm{Lit} / \mathrm{m}^{3}\right]}\end{array}$ & $\begin{array}{c}\text { 6-PVA } \\
{\left[\mathrm{kg} / \mathrm{m}^{3}\right]}\end{array}$ & $\begin{array}{c}\text { 12-PVA } \\
{\left[\mathrm{kg} / \mathrm{m}^{3}\right]}\end{array}$ \\
\hline Control & 301 & 129 & 635 & 390 & 700 & 151 & 1.215 & 0 \\
6-PVA-0.125 & 301 & 129 & 635 & 390 & 700 & 151 & 1.867 & 1.613 \\
6-PVA-0.250 & 301 & 129 & 635 & 390 & 700 & 151 & 1.774 & 3.225 \\
6-PVA-0.375 & 301 & 129 & 635 & 390 & 700 & 151 & 2.143 & 4.838 \\
6-PVA-0.500 & 301 & 129 & 635 & 390 & 700 & 151 & 2.143 & 6.450 \\
12-PVA-0.125 & 301 & 129 & 635 & 390 & 700 & 151 & 2.338 & 0 & 0 \\
12-PVA-0.250 & 301 & 129 & 635 & 390 & 700 & 151 & 2.468 & 0 & 0 \\
12-PVA-0.375 & 301 & 129 & 635 & 390 & 700 & 151 & 2.597 & 0 & 3.613 \\
12-PVA-0.500 & 301 & 129 & 635 & 390 & 700 & 151 & 3.506 & 0 & 0 \\
\hline
\end{tabular}

${ }^{1} \mathrm{~W} / \mathrm{C}$ (water/cementitious materials) ratio maintained at a constant rate of 0.35 (by weight) for all mixes.

TABLE 5: Fresh properties of FRC and control.

\begin{tabular}{|c|c|c|c|c|c|c|c|}
\hline Mix reference & $\begin{array}{c}V_{f} \\
{[\%]}\end{array}$ & $\begin{array}{c}\text { Fibre length } \\
{[\mathrm{mm}]}\end{array}$ & $\begin{array}{c}\mathrm{HWR} / \mathrm{C} \\
{[\%]}\end{array}$ & $\begin{array}{l}\text { Slump }^{1} \\
{[\mathrm{~mm}]}\end{array}$ & $\begin{array}{c}\text { Air content }^{1} \\
{[\%]}\end{array}$ & $\begin{array}{c}\text { Mass per unit volume } \\
{\left[\mathrm{kg} / \mathrm{m}^{3}\right]}\end{array}$ & Compacting factor \\
\hline Control & 0 & 0 & 0.33 & 75 & 1.0 & 2450 & 0.85 \\
\hline 6-PVA-0.125 & 0.125 & 6 & 0.47 & 75 & 1.2 & 2430 & 0.84 \\
\hline 6-PVA- 0.250 & 0.250 & 6 & 0.54 & 65 & 1.4 & 2410 & 0.82 \\
\hline 6-PVA-0.375 & 0.375 & 6 & 0.59 & 65 & 1.2 & 2370 & 0.85 \\
\hline 6-PVA-0.500 & 0.500 & 6 & 0.65 & 70 & 1.4 & 2340 & 0.89 \\
\hline 12-PVA- 0.125 & 0.125 & 12 & 0.45 & 70 & 1.4 & 2420 & 0.82 \\
\hline 12-PVA- 0.250 & 0.250 & 12 & 0.54 & 60 & 1.2 & 2390 & 0.84 \\
\hline 12-PVA-0.375 & 0.375 & 12 & 0.62 & 60 & 1.1 & 2370 & 0.81 \\
\hline 12-PVA- 0.500 & 0.500 & 12 & 0.88 & 60 & 1.4 & 2300 & 0.84 \\
\hline
\end{tabular}

${ }^{1}$ Slump, air content, and mass per unit volume calculated to the nearest $5 \mathrm{~mm}, 0.2 \%$, and $10 \mathrm{~kg} / \mathrm{m}^{3}$, respectively, in accordance with AS 1012.3 .1$, AS 1012.4 .2 , and AS 1012.5.

By viewing the results in Table 6 and Figure 5, it can be noted that with the same fibre volume fraction, shorter fibres evidently have improved the compressive strength more than longer fibres (e.g., $2.5 \%$ to $11.7 \%$ at 28 days). Similar observations for other types of synthetic fibres (i.e., polypropylene fibres) have previously been reported by other researchers $[31,32]$ that increasing the length of plastic fibres leads to a lower compressive strength. Furthermore, the optimum fibre volume fraction was found to be $0.25 \%$ across all ages with a $13.8 \%$ increase in 56-day compressive strength noted compared to the control.

Static chord modulus of elasticity of FRC and control after 7, 28, and 56 days of curing is compared in Table 7. From the results, it can be noted that modulus of elasticity of concrete PVA-FRC mixes increases with age of curing. It was also found that PVA fibres in low volume fractions used in this study $(<0.50 \%)$ do not significantly affect the modulus of elasticity although some fluctuations in the results have been observed. These variations are more noticeable after early ages ( 7 and 28 days), while after 56 days most FRC mixes have very close values to that of control. These observations were also previously reported by other researchers $[33,34]$ that fibres of different types with various modulus of elasticity do not significantly affect the static elastic moduli of concrete, due to the low fibre content. However, it is anticipated that, within the FRC, adding more fibres leads to a decrease in concrete modulus of elasticity and for the same fibre content longer fibres lead to lower MOE of the concrete.

3.3. Shrinkage and Mass Loss. The loss of water with respect to time for the FRC versus control concrete is shown in Figure 6. Large increases in mass loss were noted in all the $12 \mathrm{~mm}$ PVA-FRC. The 12-PVA- 0.125 exhibited a mass loss of $1.6 \%$ after 7 days of air storage compared to the control mix's mass loss value of $0.95 \%$. This observation suggests that the mass loss in 12-PVA- 0.125 is $70 \%$ more than the mass loss of the control at 7 days. From Figure 6, it is evident that all PVAFRC mixes exhibited higher mass loss at 7 days. This may be possibly due to the presence of more voids as a consequence of adding fibres which increases the amounts of entrapped air.

From the plotted data in Figure 6, the 12-PVA- 0.125 shows the highest mass loss with a maximum value attained after 112 days. It can be concluded that the shorter fibres generally performed better than the longer fibres. It can be seen in 
TABLE 6: Compressive strength of control and FRC at 7, 28, and 56 days.

\begin{tabular}{|c|c|c|c|c|c|c|}
\hline \multirow{2}{*}{$\begin{array}{l}\text { Mix } \\
\text { designation }\end{array}$} & \multicolumn{2}{|c|}{ 7-day strength $-f_{c, 7}$} & \multicolumn{2}{|c|}{ 28-day strength $-f_{c, 28}$} & \multicolumn{2}{|c|}{ 56-day strength $-f_{c, 56}$} \\
\hline & $\begin{array}{c}\text { Average strength }^{\mathrm{a}} \\
{\left[\mathrm{MPa} \pm \mathrm{SD}^{\mathrm{b}}\right]}\end{array}$ & $\begin{array}{c}\text { Strength effectiveness } \\
{[\%]}\end{array}$ & $\begin{array}{c}\text { Average strength } \\
{[\mathrm{MPa} \pm \mathrm{SD}]}\end{array}$ & $\begin{array}{c}\text { Strength effectiveness } \\
{[\%]}\end{array}$ & $\begin{array}{c}\text { Average strength } \\
{[\mathrm{MPa} \pm \mathrm{SD}]}\end{array}$ & $\begin{array}{c}\text { Strength effectiveness } \\
{[\%]}\end{array}$ \\
\hline Control & $46.0 \pm 1.7$ & N/A & $60.0 \pm 3.2$ & N/A & $72.5 \pm 3.0$ & N/A \\
\hline 6-PVA-0.125 & $45.0 \pm 0.5$ & -2.1 & $65.0 \pm 4.6$ & +8.3 & $79.0 \pm 2.1$ & +9.0 \\
\hline 6-PVA- 0.250 & $48.0 \pm 4.1$ & +4.3 & $67.0 \pm 3.2$ & +11.7 & $82.5 \pm 4.2$ & +13.8 \\
\hline 6-PVA-0.375 & $43.0 \pm 1.8$ & -6.5 & $62.0 \pm 2.3$ & +3.3 & $73.5 \pm 2.6$ & +1.4 \\
\hline 6-PVA- 0.500 & $40.5 \pm 3.5$ & -12.0 & $61.5 \pm 2.5$ & +2.5 & $70.0 \pm 3.8$ & -3.4 \\
\hline 12-PVA-0.125 & $41.5 \pm 1.0$ & -9.7 & $63.0 \pm 1.8$ & +5.0 & $70.5 \pm 2.8$ & -2.8 \\
\hline 12-PVA- 0.250 & $43.5 \pm 3.6$ & -5.4 & $64.5 \pm 3.2$ & +7.5 & $73.0 \pm 2.9$ & +0.7 \\
\hline 12-PVA-0.375 & $41.0 \pm 2.6$ & -10.9 & $60.0 \pm 1.7$ & 0.00 & $67.5 \pm 1.5$ & -6.9 \\
\hline 12-PVA- 0.500 & $39.5 \pm 2.4$ & -14.1 & $58.5 \pm 2.8$ & -2.5 & $64.0 \pm 4.2$ & -11.7 \\
\hline
\end{tabular}

${ }^{a}$ Average compressive strength of the test specimens calculated to the nearest $0.5 \mathrm{MPa}$ in accordance with AS 1012.9.

${ }^{\mathrm{b}} \mathrm{SD}$ : standard deviation (reported out of 3 specimens tested for each age).

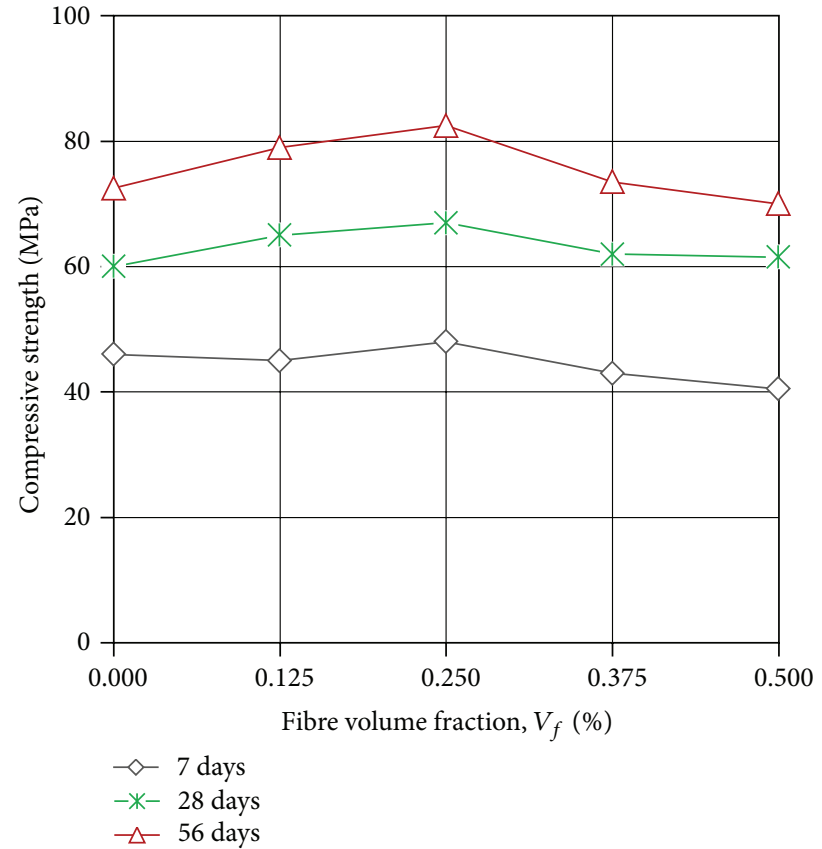

(a)

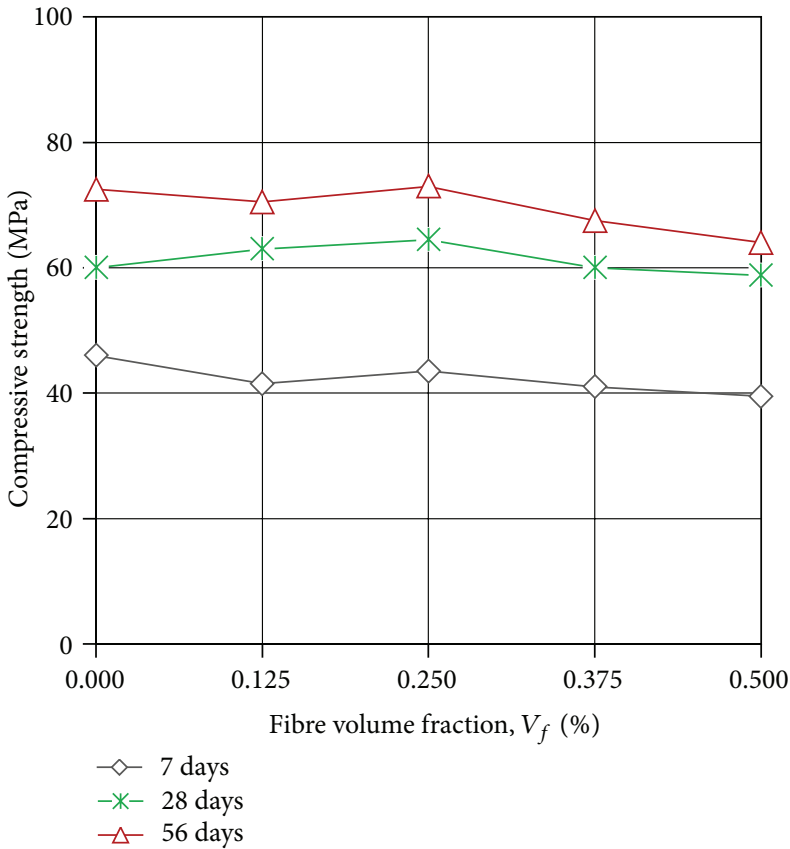

(b)

FIgURE 5: Compressive strength versus fibre content at 7, 28, and 56 days; FRC with $6 \mathrm{~mm}$ fibres (a) and FRC with $12 \mathrm{~mm}$ fibres (b).

Figure 6 that the most desirable mix in terms of mass loss was calculated to be 6-PVA-0.250 with the least amount of mass loss in comparison to all other mixes.

The shrinkage-time relationship, developed over a period of 112 days of air storage, is shown in Figures 7 and 8. All PVA-FRC mixes were found to exhibit a higher total drying shrinkage than the control between 0 to 112 days. In addition, the longer fibres exhibited higher shrinkage than the shorter fibres. The highest shrinkage of $390 \mu$-strain was exhibited by the $6 \mathrm{~mm}$ fibres up to 28, while this value was $420 \mu$ strain for the $12 \mathrm{~mm}$ fibre mixes. Nonetheless, the control only exhibited shrinkage of $320 \mu$-strain which was significantly lower than the PVA-FRC mixes.
The normalized early age (up to 7 days) shrinkage results of FRC with respect to the control concrete are presented in Figure 9. The control exhibited less shrinkage (i.e., $4.6 \%$ lower shrinkage) than all PVA-FRC mixes except for 6PVA- 0.500 incorporating $0.5 \%$ of $6 \mathrm{~mm}$ fibres. The 6-PVA0.250 displayed $110 \%$ more shrinkage than the control after 7 days. Furthermore, the 12-PVA-0.250 mix also exhibited the highest amount of shrinkage than the other $12 \mathrm{~mm}$ FRC with $75 \%$ more shrinkage than the control.

The $6 \mathrm{~mm}$ PVA-FRC exhibited less shrinkage than all $12 \mathrm{~mm}$ PVA-FRC except for the 6-PVA-0.250 mix. The 6PVA-0.500 mix also displayed the most desirable results for early age shrinkage. 
TABLE 7: Elastic modulus of control and FRC at 7, 28, and 56 days.

\begin{tabular}{lccc}
\hline Mix reference & $E_{c, 7}{ }^{\mathrm{a}}[\mathrm{GPa}]$ & $E_{c, 28}[\mathrm{GPa}]$ & $E_{c, 56}[\mathrm{GPa}]$ \\
\hline Control & 37.7 & 39.3 & 41.4 \\
6-PVA-0.125 & 37.6 & 39.5 & 41.4 \\
6-PVA-0.250 & 39.0 & 40.1 & 41.9 \\
6-PVA-0.375 & 35.9 & 39.0 & 41.0 \\
6-PVA-0.500 & 33.3 & 38.8 & 40.0 \\
12-PVA-0.125 & 33.7 & 39.0 & 39.9 \\
12-PVA-0.250 & 35.0 & 39.2 & 40.3 \\
12-PVA-0.375 & 33.6 & 38.5 & 39.7 \\
12-PVA-0.500 & 32.1 & 33.2 & 38.7 \\
\hline
\end{tabular}

${ }^{a}$ Elastic modulus of the test specimens calculated to the nearest $0.1 \mathrm{GPa}$ in accordance with AS 1012.17.

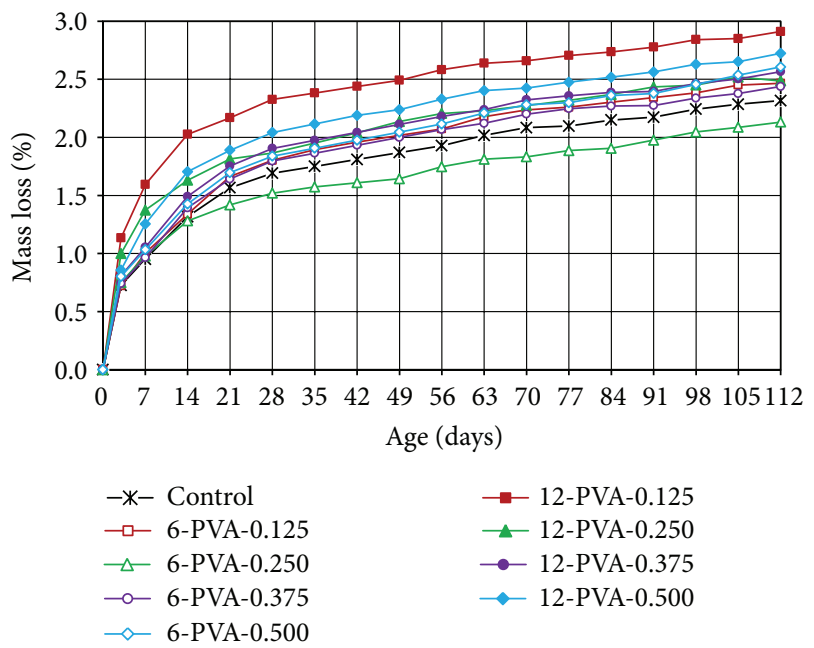

FIGURE 6: Water loss proportion to specimen initial total mass.

Short-term (up to 28 days) shrinkage results of FRC normalized to the control concrete are shown in Figure 10. From the plotted shrinkage data, the control shows the lowest shrinkage at 28 days than all PVA-FRC mixes. At early age ( 7 days), the 6-PVA-0.500 displayed the most desirable result. This mix continued to show signs of less shrinkage when compared to all other mixes apart from the control, which exhibited only $9.5 \%$ higher shrinkage after 28 days than the control. The most undesirable result was found to be the 12PVA- 0.125 mix, which exhibited $30 \%$ higher shrinkage than the control.

Figure 11 shows the normalized long-term (up to 112 days) shrinkage of FRC with respect to the control concrete. All FRC mixes show very similar values for drying shrinkage compared to the control.

A conclusion which could be drawn from the results presented in Figures 7 and 8 is that the effect of shrinkage is more significant during the early stages of drying.

The relation between the mass of water lost and shrinkage is shown in Figure 12. It should be noted that the mass of water lost is not correlated with the change in the total volume of the hardened concrete sample. Initial water loss may cause little or no shrinkage [6]. However, the evaporation of adsorbed

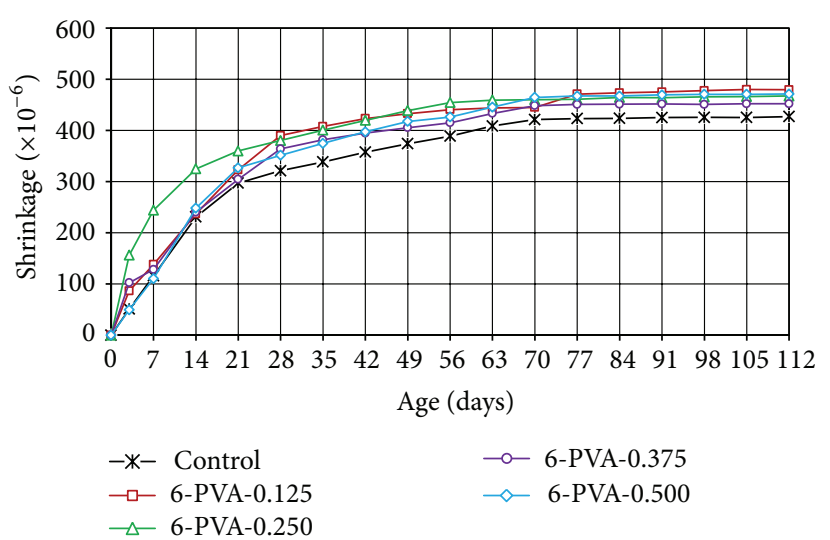

Figure 7: Shrinkage of $6 \mathrm{~mm}$ PVA-FRC and control.

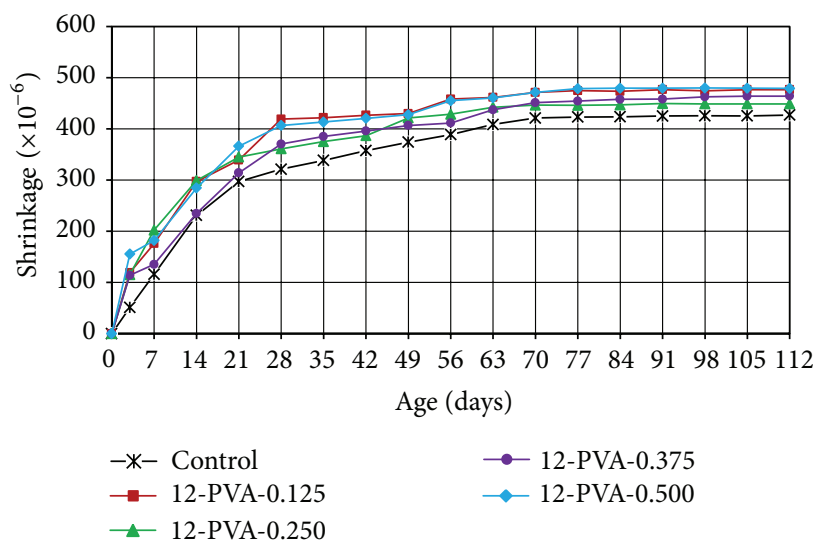

FIGURE 8: Shrinkage of $12 \mathrm{~mm}$ PVA-FRC and control.

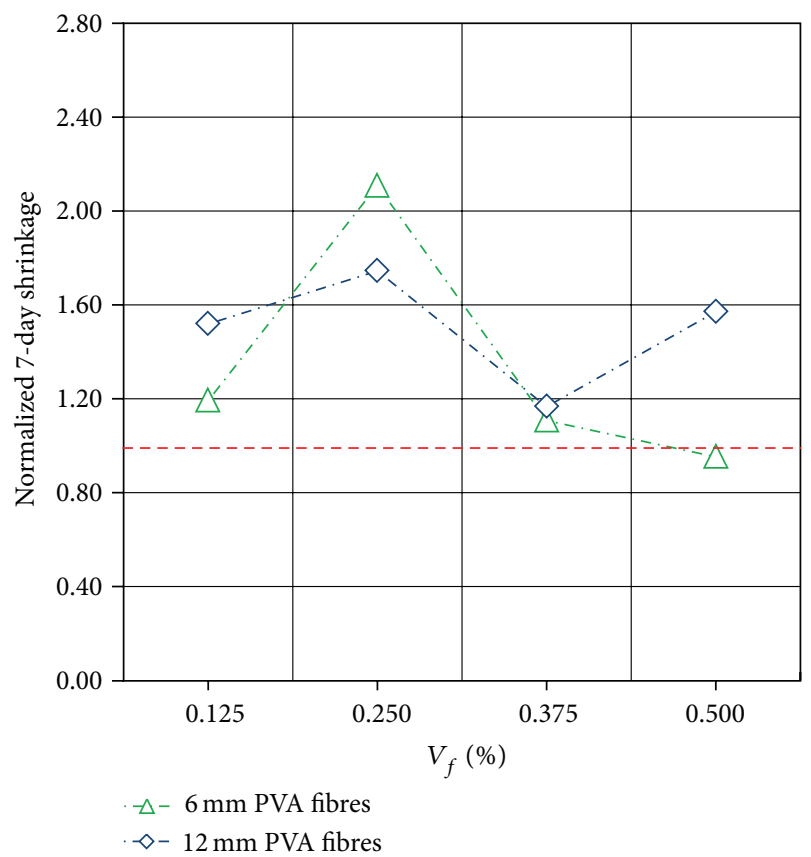

FIGURE 9: Normalized shrinkage of FRC at 7 days with respect to the control concrete. 


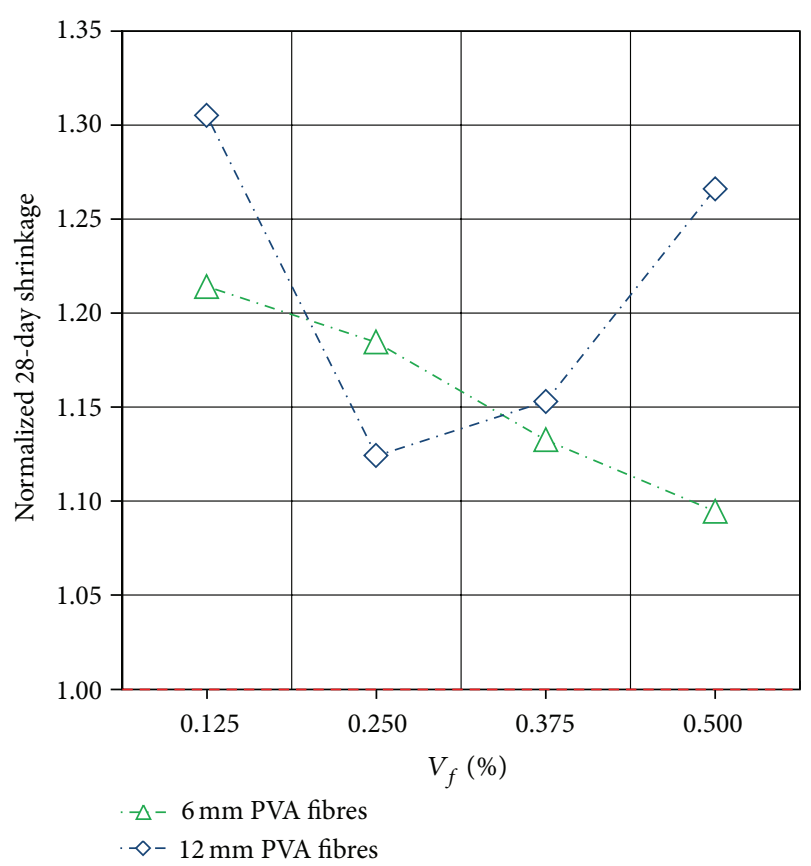

FIGURE 10: Normalized shrinkage of FRC at 28 days with respect to the control concrete.

water along the surface layers of the concrete will cause a change in volume. This change in volume is more or less equal to the loss of a water layer one molecule thick from the surface of all gel particles [6]. Emptying of the capillary pores causes a loss of water without a significant amount of shrinkage. This can be seen from the first segment of the graph in Figure 12 (up to mass loss equal to 30 grams). The results show that mixes incorporating PVA fibres should have lower amounts of capillary pores and free water compared to the control concrete since lower mass loss is recorded for FRC. However, once the water from the capillary pores has been lost, the removal of absorbed water causes shrinkage in almost the same manner as the control concrete for most PVA-FRC mixes. This interaction justifies similar behaviour towards the last segment of the graph.

From the shrinkage results plotted against the corresponding mass loss for different mixes in Figure 12, it is observed that an almost linear relationship is displayed between shrinkage and mass loss, which complies with previous investigations [35-37].

\section{Summary and Conclusions}

The following conclusions can be drawn based on the results obtained in this study.

(a) The introduction of PVA fibres decreased the workability of the mix. More HWR was required to achieve a desirable slump. With a fibre volumetric content above or close to $0.5 \%$, the workability is known to decrease due to greater interfacial actions during mixing between the fibres and cementitious materials in concrete [19]. Furthermore, mixes with longer fibre

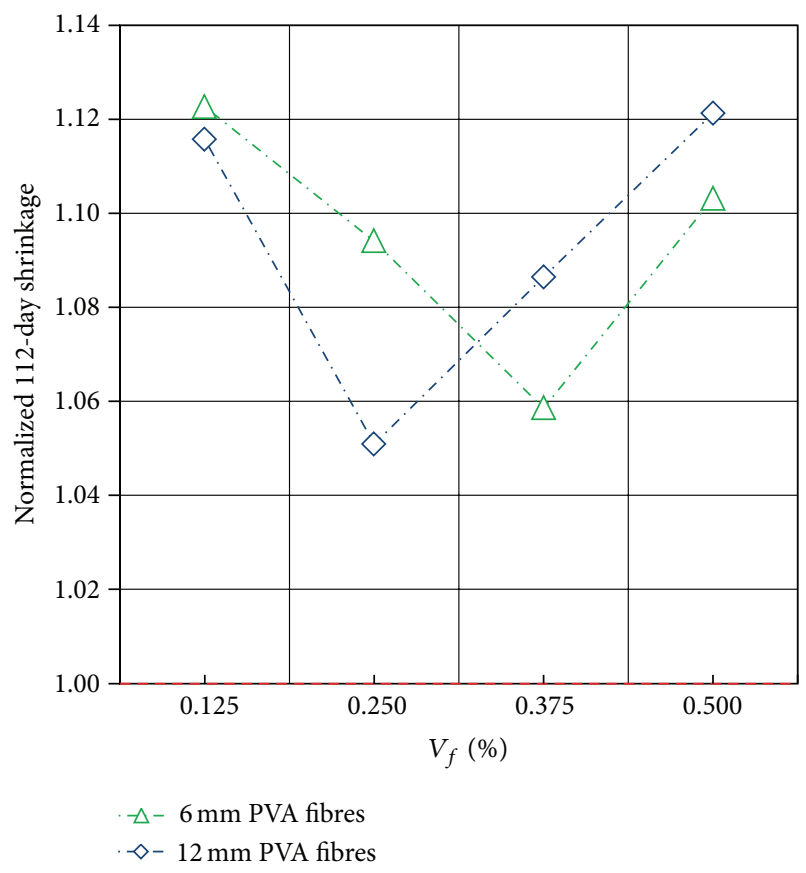

FIGURE 11: Normalized shrinkage of FRC at 112 days with respect to the control concrete.

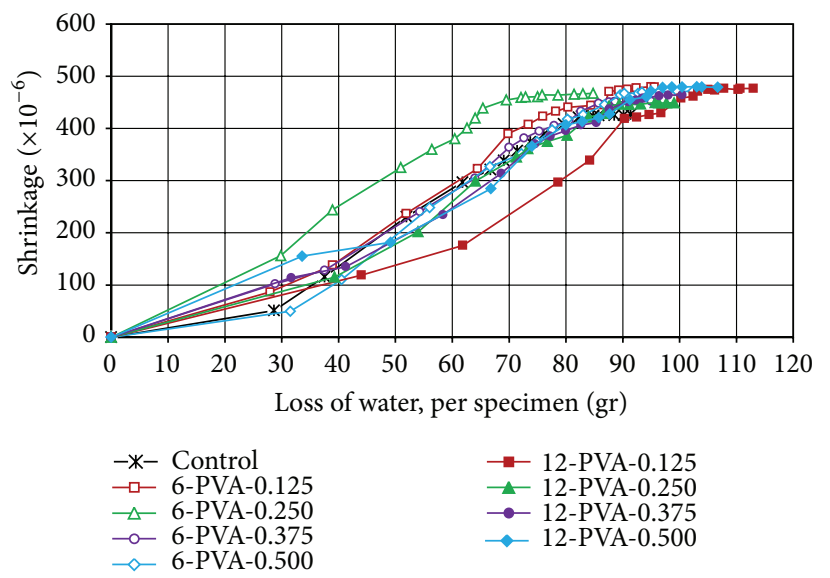

FIGURE 12: Relation between shrinkage and loss of water from specimens.

length demonstrate lower slump compared to shorter fibre length for the same fibre volume addition.

(b) The compressive strength results show that almost all PVA incorporated mixes exhibited lower compressive strength than the control after 7 days of curing. On a positive note, this trend was found to reverse after 28 days of curing. Almost all PVA incorporated mixes exhibited higher compressive strength than the control at 28 days. It is worth noting that, with the same fibre volume fraction, shorter fibres enhance compressive strength more than longer fibres. Furthermore, the optimum fibre volume fraction was found to be $0.25 \%$ for all curing ages with a $13.8 \%$ 
increase noted in 56-day compressive strength compared to the control.

(c) Test results show that PVA fibres in low volume fractions used in this study $(<0.50 \%)$ do not significantly affect the modulus of elasticity.

(d) The shrinkage results of FRC and control concrete up to 112 days indicated that all PVA-FRC mixes exhibited higher drying shrinkage than the control. In addition, longer fibres exhibited higher mass loss, thus potentially contributing to higher shrinkage. This may be due to the hydrophilic nature of PVA fibres absorbing water during the fresh state of concrete and releasing this absorbed water as concrete was hardened.

As it has been previously reported by many researchers $[33,38,39]$, the incorporation of polymeric fibres in concrete in low volume fraction $(<1 \%)$ is mostly recognised to be effective in controlling and mitigating the susceptibility to plastic shrinkage cracking. However, the results of this study showed the reverse. Accordingly, it can be stated that in cases where reducing concrete shrinkage is important, the use of virgin (uncoated) PVA fibre should be avoided. In such cases, a surface agent in the form of an oil may be applied to the surface of the PVA fibres to make them more hydrophobic [15]. The introduction of an oil base surface treatment agent would also suggest that the fibre-matrix bond characteristics and PVA fibre performance are improved within the matrix and the composite mechanical properties and toughness are also enhanced [40-43].

\section{Conflict of Interests}

The authors declare that there is no conflict of interests regarding the publication of this paper.

\section{Acknowledgment}

The authors would like to acknowledge the support from the Centre for Built Infrastructure Research (CBIR) at the University of Technology Sydney (UTS).

\section{References}

[1] A. M. Alhozaimy and M. J. Shannag, "Performance of concretes reinforced with recycled plastic fibres," Magazine of Concrete Research, vol. 61, no. 4, pp. 293-298, 2009.

[2] J. J. Park, D. Yoo, S. Kim, and Y. Yoon, "Drying shrinkage cracking characteristics of ultra-high-performance fibre reinforced concrete with expansive and shrinkage reducing agents," Magazine of Concrete Research, vol. 65, pp. 248-256, 2013.

[3] K. Sakata, "A study on moisture diffusion in drying and drying shrinkage of concrete," Cement and Concrete Research, vol. 13, no. 2, pp. 216-224, 1983.

[4] B. I. G. Barr and A. S. A. El-Baden, "Shrinkage properties of normal and high strength fibre reinforced concrete," Proceedings of the Institution of Civil Engineers: Structures and Buildings, vol. 156, no. 1, pp. 15-25, 2003.
[5] Cement Concrete \& Aggregates Australia, Drying Shrinkage of Cement and Concrete, C.C.A.A., 2002.

[6] A. Neville, Properties of Concrete, 4th and Final Edition, John Wiley \& Sons, 1991.

[7] C. M. Tam, V. W. Y. Tam, and K. M. Ng, "Assessing drying shrinkage and water permeability of reactive powder concrete produced in Hong Kong," Construction and Building Materials, vol. 26, no. 1, pp. 79-89, 2012.

[8] G. W. Wash, "Volume changes of hardened concrete. Significance of tests and properties of concrete and concrete-making materials," ASTM (STP 169-A), American Society for Testing and Materials, Philadelphia, Pa, USA, 1996.

[9] M. Grzybowski and S. P. Shah, "Shrinkage cracking of fiber reinforced concrete," ACI Materials Journal, vol. 87, no. 2, pp. 138-148, 1990.

[10] S. W. Kim, J. J. Park, S. T. Kang, G. S. Ryo, and K. T. Koh, "Development of ultra high performance cementitious composites (UHPCC) in Korea," in Proceedings of the 4th International Conference on Bridge Maintenance (IABMAS '08), p. 110, Seoul, Republic of Korea, July 2008.

[11] B. A. Graybeal, "Flexural behavior of an ultrahigh-performance concrete I-girder," Journal of Bridge Engineering, vol. 13, no. 6, pp. 602-610, 2008.

[12] A. Kamen, E. Denarié, H. Sadouki, and E. Brühwiler, "Thermomechanical response of UHPFRC at early age-experimental study and numerical simulation," Cement and Concrete Research, vol. 38, no. 6, pp. 822-831, 2008.

[13] B. Chen and C. Fang, "Contribution of fibres to the properties of EPS lightweight concrete," Magazine of Concrete Research, vol. 61, no. 9, pp. 671-678, 2009.

[14] A. Noushini, B. Samali, and K. Vessalas, "Effect of polyvinyl alcohol (PVA) fibre on dynamic and material properties of fibre reinforced concrete," Construction and Building Materials, vol. 49, pp. 374-383, 2013.

[15] H. Kong, S. G. Bike, and V. C. Li, "Constitutive rheological control to develop a self-consolidating engineered cementitious composite reinforced with hydrophilic poly(vinyl alcohol) fibers," Cement and Concrete Composites, vol. 25, no. 3, pp. 333341, 2003.

[16] V. C. Li and S. Wang, "Microstructure variability and macroscopic composite properties of high performance fiber reinforced cementitious composites," Probabilistic Engineering Mechanics, vol. 21, no. 3, pp. 201-206, 2006.

[17] D. Feldman, Polymeric Building Materials, Elsevier Applied Science, London, UK, 1989.

[18] B. Xu, H. A. Toutanji, and J. Gilbert, "Impact resistance of poly(vinyl alcohol) fiber reinforced high-performance organic aggregate cementitious material," Cement and Concrete Research, vol. 40, no. 2, pp. 347-351, 2010.

[19] R. F. Zollo, "Fiber-reinforced concrete: an overview after 30 years of development," Cement and Concrete Composites, vol. 19, no. 2, pp. 107-122, 1997.

[20] S. B. Daneti, T. Wee, and T. Thangayah, "Effect of polypropylene fibres on the shrinkage cracking behaviour of lightweight concrete," Magazine of Concrete Research, vol. 63, no. 11, pp. 871881, 2011

[21] B. Arisoy, Development and Fracture Evaluation of High Performance Fiber Reinforced Lightweight Concrete, Wayne State University, 2002.

[22] S. B. Daneti and T. Wee, "Behaviour of hybrid fibre reinforced high-strength lightweight aggregate concrete," Magazine of Concrete Research, vol. 63, no. 11, pp. 785-796, 2011. 
[23] ACI-Comittee 544, "State-of-the-art report on fiber reinforced concrete," Tech. Rep. A. 544. 1R-96, American Concrete Institute, 2002.

[24] D. Nicolaides, A. Kanellopoulos, and B. L. Karihaloo, "Fatigue life and self-induced volumetric changes of CARDIFRC," Magazine of Concrete Research, vol. 62, no. 9, pp. 679-683, 2010.

[25] J. Zhang, H. Stang, and V. C. Li, "Crack bridging model for fibre reinforced concrete under fatigue tension," International Journal of Fatigue, vol. 23, no. 8, pp. 655-670, 2001.

[26] R. Combrinck and W. P. Boshoff, "Typical plastic shrinkage cracking behaviour of concrete," Magazine of Concrete Research, vol. 65, pp. 486-493, 2013.

[27] H. Wu and V. C. Li, "Trade-off between strength and ductility of random discontinuous fiber reinforced cementitious composites," Cement and Concrete Composites, vol. 16, no. 1, pp. 23-29, 1994.

[28] BSI, BS, 8110 Part 2, Structural Use of Concrete. Code of Practice for Design and Construction, BSI, London, UK, 1985.

[29] A. Izaguirre, J. Lanas, and J. I. Alvarez, "Effect of a polypropylene fibre on the behaviour of aerial lime-based mortars," Construction and Building Materials, vol. 25, no. 2, pp. 992-1000, 2011.

[30] N. Ghosni, K. Vessalas, and B. Samali, "Evaluation of fresh properties effect on the compressive strength of polypropylene fibre reinforced polymer modified concrete," in Proceedings of the 22nd Australasian Conference on the Mechanics of Structures and Materials (ACMSM '12), Sydney, Australia, 2012.

[31] D. V. Soulioti, N. M. Barkoula, A. Paipetis, and T. E. Matikas, "Effects of fibre geometry and volume fraction on the flexural behaviour of steel-fibre reinforced concrete," Strain, vol. 47, no. 1, pp. e535-e541, 2011.

[32] M. A. O. Mydin and S. Soleimanzadeh, "Effect of polypropylene fiber content on flexural strength of lightweight foamed concrete at ambient and elevated temperatures," Advances in Applied Science Research, vol. 3, no. 5, pp. 2837-2846, 2012.

[33] D. J. Hannant, "Fibre-reinforced concrete," in Advanced Concrete Technology Set, J. Newman and B. S. Choo, Eds., pp. 6/16/17, Butterworth-Heinemann, Oxford, UK, 2003.

[34] V. Corinaldesi and G. Moriconi, "Characterization of selfcompacting concretes prepared with different fibers and mineral additions," Cement and Concrete Composites, vol. 33, no. 5, pp. 596-601, 2011.

[35] A. Bentur and A. Goldman, "Curing effects, strength and physical properties of high strength silica fume concretes," Journal of Materials in Civil Engineering, vol. 1, no. 1, pp. 46-58, 1989.

[36] E. El Hindy, B. Miao, O. Chaallal, and P. Aitcin, "Drying shrinkage of ready-mixed high-performance concrete," ACI Materials Journal, vol. 91, no. 3, pp. 300-305, 1994.

[37] S. Ghosh and K. W. Nasser, "Creep, shrinkage, frost, and sulphate resistance of high strength concrete," Canadian Journal of Civil Engineering, vol. 22, no. 3, pp. 621-636, 1995.

[38] A. Bentur and S. Mindess, Fiber Reinforced Cementitious Composites, Elsevier Applied Science, 1990.

[39] P. N. Balaguru and S. P. Shah, Fiber Reinforced Cement Composites, McGraw Hill, 1992.

[40] B. Felekoğlu, K. Tosun, and B. Baradan, "Effects of fibre type and matrix structure on the mechanical performance of selfcompacting micro-concrete composites," Cement and Concrete Research, vol. 39, no. 11, pp. 1023-1032, 2009.

[41] C. Redon, V. C. Li, C. Wu, H. Hoshiro, T. Saito, and A. Ogawa, "Measuring and modifying interface properties of PVA fibers in ECC matrix," Journal of Materials in Civil Engineering, vol. 13, no. 6, pp. 399-406, 2001.

[42] V. C. Li, C. Wu, S. Wang, A. Ogawa, and T. Saito, "Interface tailoring for strain-hardening polyvinyl alcohol-engineered cementitious composite (PVA-ECC)," ACI Materials Journal, vol. 99, no. 5, pp. 463-472, 2002.

[43] V. C. Li, T. Kanda, and Z. Lin, "The influence of fibre/matrix interface properties on complementary energy and composite damage tolerance," in Proceedings of the 3rd Conference on Fracture and Strength of Solids, Hong Kong, 1997. 

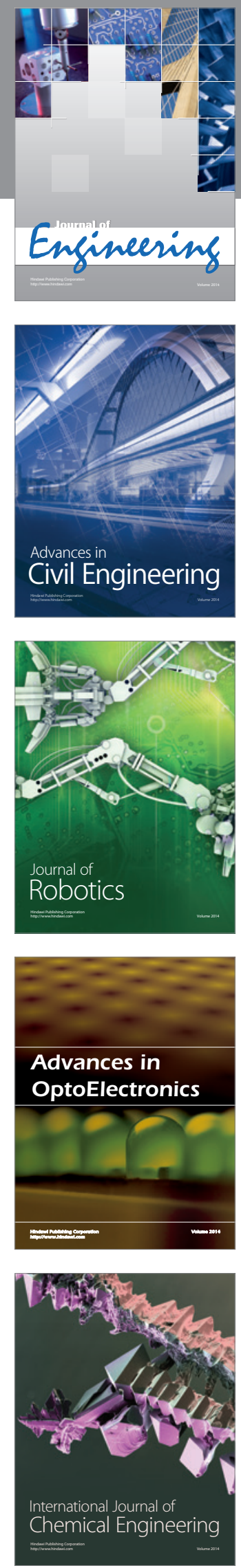

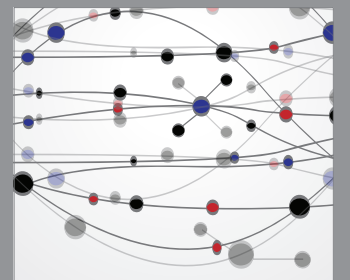

The Scientific World Journal
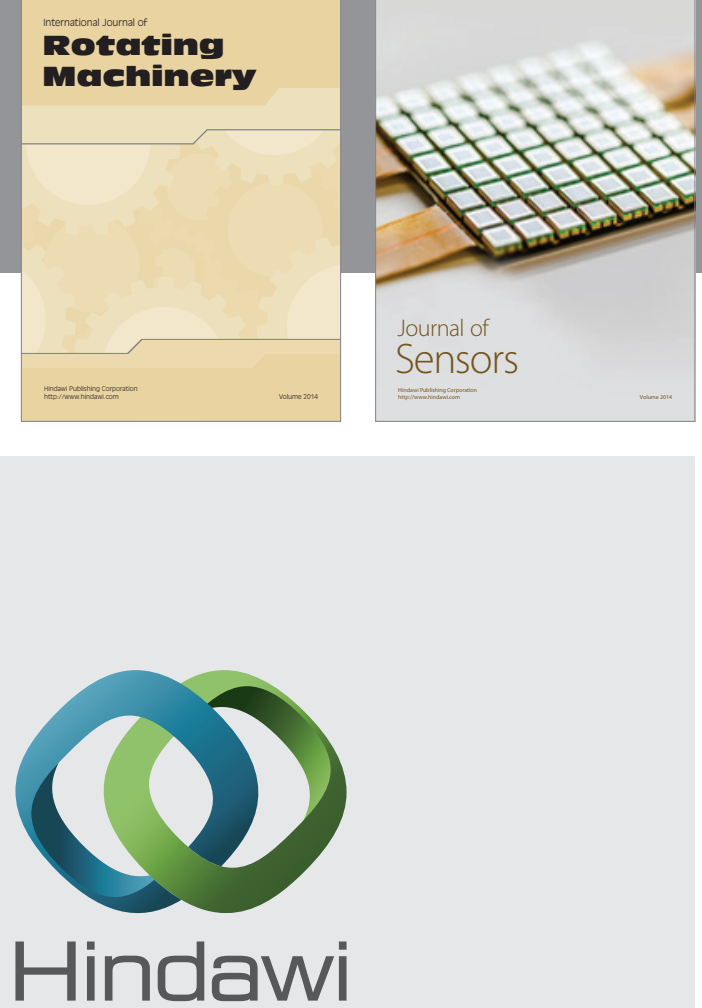

Submit your manuscripts at http://www.hindawi.com
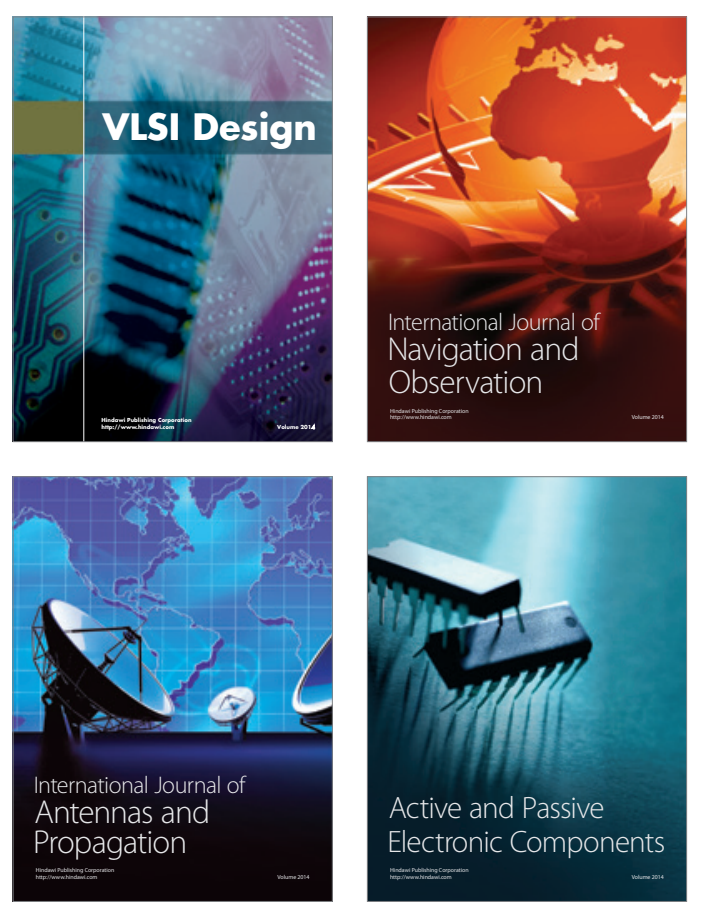
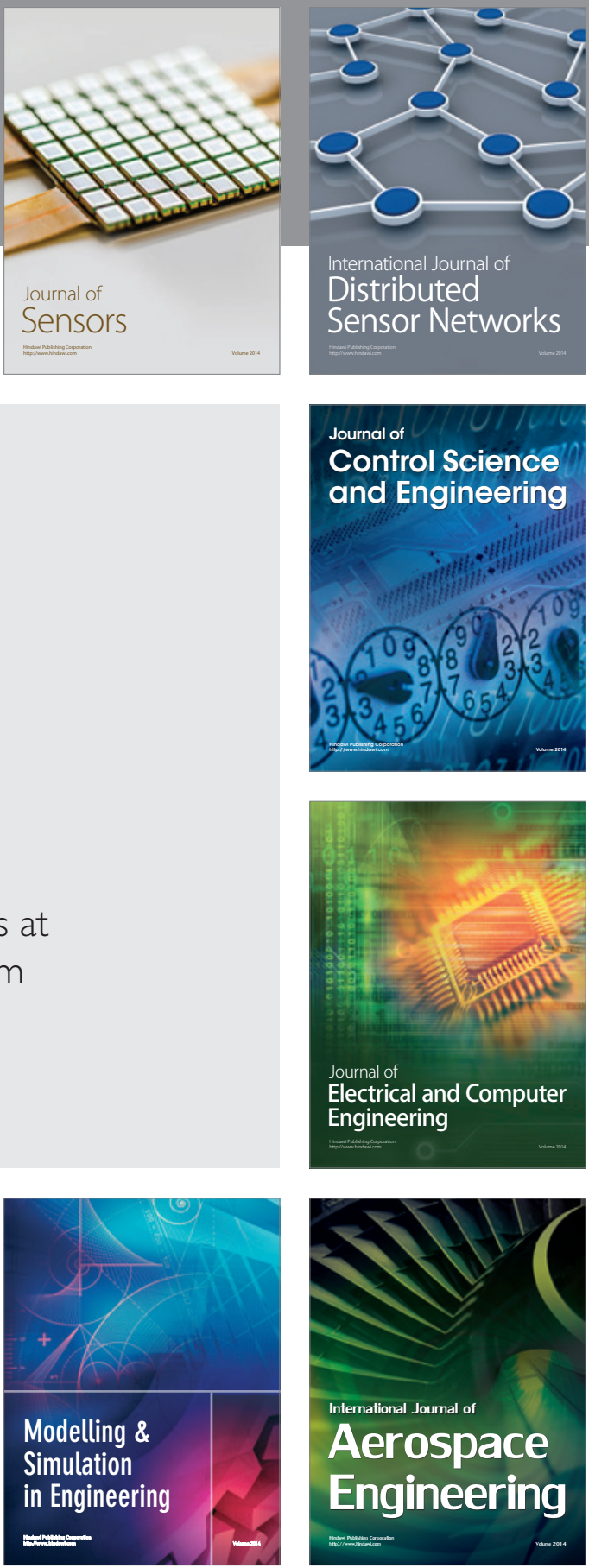

Journal of

Control Science

and Engineering
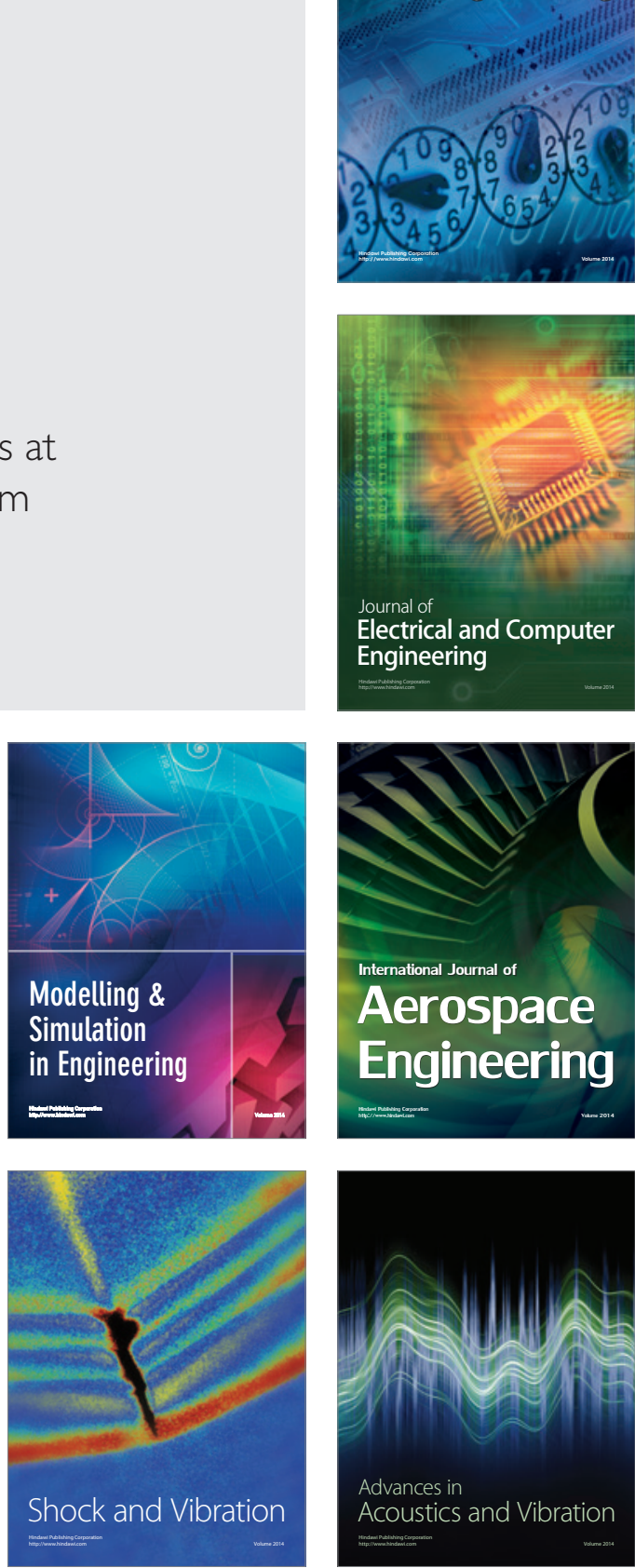